九州大学学術情報リポジトリ

Kyushu University Institutional Repository

\title{
In Vitro Induction of Aneuploid Forms of Tetraploid Grapes by para-Fluorophynylalanine
}

Sarikhani, Hassan

Graduate School of Bioresource and Bioenvironmental Science, Kyushu University

Wakana, Akira

Faculty of Agriculture, Kyushu University

https://doi.org/10.5109/9238

出版情報: 九州大学大学院農学研究院紀要. 51 (2)，pp.257-260，2006-10-27. Faculty of Agriculture, Kyushu University

バージョン :

権利関係 : 


\title{
In Vitro Induction of Aneuploid Forms of Tetraploid Grapes by para-Fluorophenylalanine
}

\author{
Hassan SARIKHANI ${ }^{1}$ and Akira WAKANA* \\ Laboratory of Horticultural Science, Division of Agricultural Botany, Department of \\ Plant Resources, Faculty of Agriculture, Kyushu University, Fukuoka 812-8581 \\ (Received June 30, 2006 and accepted July 24, 2006)
}

\begin{abstract}
Direct induction of hyper- and hypo-tetraploid forms ( $2 \mathrm{n}=4 \mathrm{x} \pm 1$ or $4 \mathrm{x} \pm 2$ ) from tetraploid grapes without crossings may be useful for establishing seedlessness in the seeded cultivars without greatly loosing their vigor and other characters. For the induction, explants proliferated from cultured shoot tips of tetraploid 'Kyoho', 4x 'Rozaki' and hybrids from 'Kyoho’× '4x Rizamato' cross were treated for 30 and 60 days on MS medium supplemented with various concentrations of para-fluorophenylalanine (PFP; 25-150 mg/l), and subcultured for about three months on rooting medium lacking PFP. Of 348 explants including those of control, 233 explants survived. Of the survived explants, 208 tetraploid $(2 \mathrm{n}=4 \mathrm{x}=76)$, six mixoploid consisting of cells with 76 and those with less than 76 chromosomes and two aneuploid plants $(2 n=72$ and 69$)$ were identified by the chromosome observation in their root tip cells; chromosomal variation in 17 explants showing no growth and rooting could not be identified. With increase of the PFP concentration, the rates of survived explants and explants showing no growth increased. Treatment of $75-150 \mathrm{mg} / \mathrm{l} \mathrm{PFP}$ for 30 and 60 days was effective for elimination of a few chromosomes in the tetraploid explants. The result suggested the possibility of somaclonal induction of hyper-and hypo-tetraploids from tetraploid cultivars by PFP treatment in vitro.
\end{abstract}

\section{INTRODUCTION}

Mutation or somaclonal variation is one of the most useful tools in breeding of vegetatively propagated plants such as fruit trees. Mutation mainly occurs at the gene or chromosome level in a given plant. Para-fluorophenylalanine ( $\mathrm{PFP}$ ), which is an amino acid analogue, alters amino acid metabolism (Widholm, 1977), inhibits mitotic spindle formation (Thao et al., 2003) and, subsequently, reduces chromosome number to haploid number in the daughter cells (Lhoas, 1961). The effect of PFP on the reduction of chromosome number has been firstly reported in diploid Aspergillus niger from which haploid cells were induced (Lhoas, 1961). After this report, similar effects of PFP have been described in many plants such as Ribes (Knight et al., 1963), Allium (Sinha and Bhojwani, 1976), Fragaria (Niizeki and Fukui, 1983) and Alocasia (Thao et al., 2003).

In Vitis, it has been reported that PFP effected on the change of chromosome number in the root cells of seedlings (Omura and Akihama, 1980; Omura et al., 1985) and induction of a triploid from PFP-treated shoots of tetraploid 'Kyoho' (Omura and Akihama, 1981). However, there are no reports as to somaclonal induction of hyper- and hypo-tetraploid grapes by PFP treatment.

Hyper - and hypo-tetraploid grapes $(2 \mathrm{n}=4 \mathrm{x} \pm 1$ or $4 \mathrm{x} \pm 2$ ) resulting from failure or irregularity of meiosis were found as a spontaneous (probably $\mathrm{S}_{1}$ ) seedling of

\footnotetext{
${ }^{1}$ Laboratory of Horticultural Science, Division of Agricultural Botany, Department of Plant Resources, Graduate School of Bioresource and Bioenvironmental Sciences, Kyushu University

* Corresponding author (E-mail: wakana@agr.kyushu-u.ac.jp)
}

'Kyoho' (Yamane et al., 1978), appeared in selfed seedlings with abnormal cotyledons in 'Kyoho' (Park et $a l ., 1999 a)$ and rarely found in hybrid seedlings from interploid crosses between triploid and tetraploid grapes (Park et al., 1999b, 2002). 'Takao', a spontaneous hypotetraploid seedling of 'Kyoho', produces almost seedless berries of small size, but it produces large seedless berries with the aid of gibberellin treated at full bloom (Ashikawa, 1972). Thus, the crossing between tetraploid cultivars, followed by selection of the resultant seedlings with abnormal cotyledons, is an excellent method to obtain hyper- and hypo-tetraploid hybrid grapes for breeding of seedless cultivars. On the other hand, direct induction of hyper- and hypo-tetraploid forms from excellent but seeded tetraploid grape cultivars without crossings may be useful for establishing seedlessness in the seeded cultivars without greatly loosing their high tree vigor and other characters such as productivity, large berry size (Reisch and Pratt, 1996; Notsuka et al., 2000) and berry quality, although high parthenocarpy is required for the original cultivars to set and produce large-sized seedless berries without gibberellin treatment.

To establish the efficient method to produce hyperand hypo-tetraploid forms, we studied the effect of in vitro PFP treatment on the small change in tetraploid chromosome number in cultured shoots of 'Kyoho', colchiploid of 'Rozaki' and 'Kyoho' hybrids, all of which are tetraploid plants with relatively high parthenocarpic ability.

\section{MATERIALS AND METHODS}

Tetraploid cultivar 'Kyoho', a colchicine-induced tetraploid form of 'Rozaki' ('Rozaki-4x') and two tetraploid hybrids KRi4x2014 and KRi4x2181 (Kyohox 
tetraploid from of 'Rizamato') were used for this study to induce their hyper- and hypo-tetraploid forms. All of these cultivars and hybrids showed relatively high parthenocarpy.

The shoots of each genotype were collected early in June and trimmed so that they were $3-5 \mathrm{~cm}$ in length and had a few young leaves. The trimmed shoots were sterilized in a solution of $0.5 \%$ sodium hypochlorite for 12 minutes and rinsed three times in distilled water. The shoot tips (0.5-2 mm in length) excised from the sterilized shoots were cultured on MS medium (Murashige and Skoog, 1962) containing 0.8\% agar, 3\% sucrose, $1 \mu \mathrm{M}$ indole-3-acetic acid (IAA) and $5 \mu \mathrm{M}$ benzyladenine (BA) for shoot multiplication. The $\mathrm{pH}$ of the medium was adjusted at 5.7 \pm 0.1. After one month of culture, multiplied shoots were transplanted on MS medium supplemented with $0.8 \%$ agar, $3 \%$ sucrose, $1 \mu \mathrm{M}$ IAA and $2 \mu \mathrm{M}$ BA for shoot growth. For the multiplied shoots of 'Kyoho', $0.2 \%$ activated charcoal was further added to the medium. After one month of the culture, shoot terminal with three or four expanded leaves was excised from the developing shoots and cultured for 30 and 60 days on MS medium containing $0.8 \%$ agar, $3 \%$ sucrose, $1 \mu \mathrm{M}$ IAA, $2 \mu \mathrm{M}$ BA and PFP. The concentration of FPF was adjusted at 0, 25, 50, 75, 100 and $150 \mathrm{mg} / \mathrm{l}$. The PFP-treated shoots were transplanted on the MS medium lacking PFP. After eight weeks of the culture (Fig. 1), developing shoots with 2-4 young leaves were excised from the explants and planted on the same medium. When the planted shoots expanded several leaves, they were subcultured on half strength MS medium with $2 \%$ sucrose to enhance their rooting.

Throughout the culture, the conditions of growth chamber (Sanyo, MLR351H) were maintained at $26^{\circ} \mathrm{C} / 21^{\circ} \mathrm{C}$ for day/night and $16 / 8$ hour photoperiod with a light intensity of about $100 \mathrm{mMcm}^{-2} \mathrm{~s}^{-1}$, and one explant was planted per vessel (Conical flask; $100 \mathrm{ml}$ ).

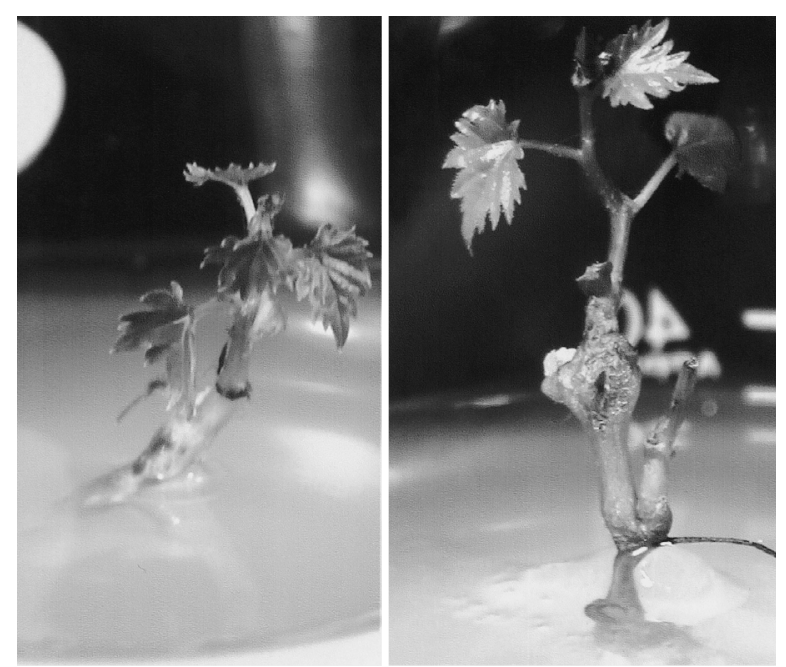

Fig. 1. In vitro treatment of grape shoots with PFP. Left: in vitro PFP treatment of shoot with four leaves. Right: A PFP-treated explant on subculture medium lacking PFP, showing new shoot development from the treated shoot.
Chromosome observation was carried out in several root tip cells according to the procedure of enzyme maceration method described by Park et al. (2001). At least three root tips were used for chromosome observation in each explant.

\section{RESULTS}

\section{Shoot proliferation and growth}

The extent of proliferation and growth of the shoot tip explants was high and almost same in different genotypes except 'Kyoho'. 'Kyoho' shoot tips cultured on initial proliferation medium containing $5 \mu \mathrm{M}$ BA were successful as those of the other genotypes. When they were transplanted on the second medium containing $2 \mu \mathrm{M} \mathrm{BA}$, however, about $60 \%$ of the explants died and the survived showed slow growth. When the explants were transplanted on the medium supplemented with $0.2 \%$ charcoal, they showed a high survival rate and the same extent of growth rate as those of 'Rozaki-4x' (Table 1).

Table 1. Effect of activated charcoal on the survival and growth of transplanted shoots of 'Kyoho' on MS medium after one-month culture

\begin{tabular}{cccc}
\hline $\begin{array}{c}\text { Concentration } \\
\text { of charcoal } \\
(\%)\end{array}$ & $\begin{array}{c}\text { No. of } \\
\text { explants } \\
\text { transplanted }\end{array}$ & $\begin{array}{c}\text { No. of } \\
\text { explants } \\
\text { survived }\end{array}$ & $\begin{array}{c}\text { Mean growth } \\
\text { rate } \\
\text { (cm/month) }\end{array}$ \\
\hline 0 & 20 & 8 & 2.4 \\
0.2 & 22 & 21 & 6.3 \\
\hline
\end{tabular}

Of 348 PFP-treated explants including control, 233 explants were survived on the medium (Table 2). The survival rate was the highest in KRi4x2014 (90\%), followed by KRi4x2181 (70.8\%), 'Kyoho' (60\%) and 'Rozaki-4x' (54.2\%). In each genotype, the rate of survived explants decreased with increase of PFP concentration. Of the 233 explants survived, 17 explants that showed very slow or no growth were observed on the medium containing more than $50 \mathrm{mg} / \ell \mathrm{PFP}$. The rate of these explants increased with increase of PFP

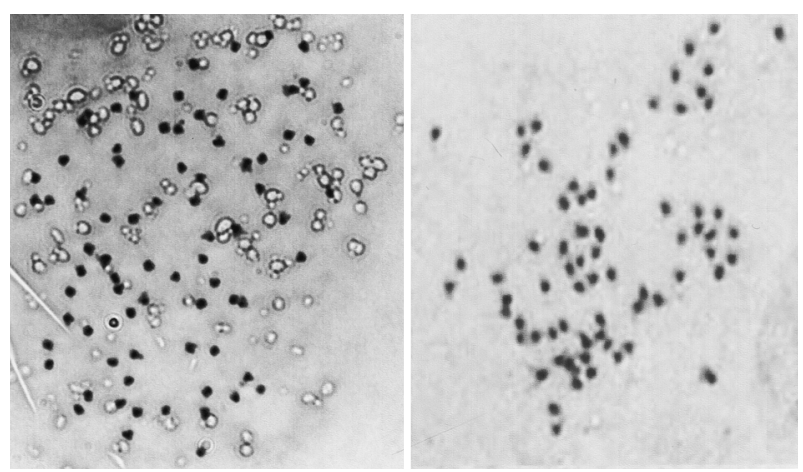

Fig. 2. Metaphase figures in root tip cells of PFP-treated explants. Left: a 'Kyoho' shoot explant without PFP treatment, showing 76 chromosomes. Right: an explant from a new shoot developing from the $150 \mathrm{mg} / \mathrm{l} \mathrm{PFP}$-treated explant of KRi4x2181 for 30 days, showing 72 chromosomes. 
Table 2. Survival rates and reduction of chromosome number in shoot tip explants treated with various concentrations of PFP in vitro in 'Kyoho', 'Rozaki-4x' and hybrid plants ('Kyoho' $\times$ 'Rozamato-4x)

\begin{tabular}{|c|c|c|c|c|c|c|c|}
\hline \multirow{2}{*}{ Genotype } & \multirow{2}{*}{$\begin{array}{c}\text { Days of } \\
\text { treatment }\end{array}$} & \multirow{2}{*}{$\begin{array}{c}\text { Concentration } \\
\text { (mg/l) }\end{array}$} & \multicolumn{2}{|c|}{ No. of explants } & \multicolumn{3}{|c|}{ No. of explants with indicated ploidy } \\
\hline & & & Treated & Survived* & Tetraploid (76) & Mixoploid & Aneuploid \\
\hline \multirow[t]{12}{*}{ Kyoho } & \multirow[t]{6}{*}{30} & 0 & 10 & $8(0)$ & 8 & 0 & 0 \\
\hline & & 25 & 10 & $9(0)$ & 9 & 0 & 0 \\
\hline & & 50 & 10 & $8(0)$ & 8 & 0 & 0 \\
\hline & & 75 & 10 & $5(0)$ & 4 & $1(71,73)$ & 0 \\
\hline & & 100 & 10 & $4(0)$ & 4 & 0 & 0 \\
\hline & & 150 & 10 & $2(1)$ & 1 & 0 & 0 \\
\hline & \multirow[t]{6}{*}{60} & 0 & 8 & $5(0)$ & 5 & 0 & 0 \\
\hline & & 25 & 8 & $5(0)$ & 5 & 0 & 0 \\
\hline & & 50 & 8 & $4(1)$ & 3 & 0 & 0 \\
\hline & & 75 & 8 & $4(0)$ & 4 & 0 & 0 \\
\hline & & 100 & 8 & $3(1)$ & 1 & $1(72,75)$ & 0 \\
\hline & & 150 & 8 & $4(2)$ & 2 & 0 & 0 \\
\hline \multirow[t]{6}{*}{ Rozaki-4x } & \multirow[t]{6}{*}{30} & 0 & 8 & $6(0)$ & 6 & 0 & 0 \\
\hline & & 25 & 8 & $6(0)$ & 6 & 0 & 0 \\
\hline & & 50 & 8 & $5(0)$ & 5 & 0 & 0 \\
\hline & & 75 & 8 & $4(0)$ & 4 & 0 & 0 \\
\hline & & 100 & 8 & $3(1)$ & 2 & 0 & 0 \\
\hline & & 150 & 8 & $2(1)$ & 1 & 0 & 0 \\
\hline \multirow{6}{*}{ KRi4x2014 } & \multirow[t]{6}{*}{30} & 0 & 10 & $10(0)$ & 10 & 0 & 0 \\
\hline & & 25 & 10 & $10(0)$ & 10 & 0 & 0 \\
\hline & & 50 & 10 & $9(0)$ & 9 & 0 & 0 \\
\hline & & 75 & 10 & $9(1)$ & 7 & $1(63,76)$ & 0 \\
\hline & & 100 & 10 & $8(0)$ & 8 & 0 & 0 \\
\hline & & 150 & 10 & $8(2)$ & 5 & 0 & $1(72)$ \\
\hline \multirow[t]{12}{*}{ KRi4x2181 } & \multirow[t]{6}{*}{30} & 0 & 12 & $12(0)$ & 12 & 0 & 0 \\
\hline & & 25 & 12 & $12(0)$ & 12 & 0 & 0 \\
\hline & & 50 & 12 & 9 (1) & 8 & 0 & 0 \\
\hline & & 75 & 12 & 7 (1) & 6 & 0 & 0 \\
\hline & & 100 & 12 & $5(0)$ & 3 & $1(65,68)$ & 1(69) \\
\hline & & 150 & 12 & $6(1)$ & 5 & 0 & 0 \\
\hline & \multirow[t]{6}{*}{60} & 0 & 10 & $10(0)$ & 10 & 0 & 0 \\
\hline & & 25 & 10 & $10(0)$ & 10 & 0 & 0 \\
\hline & & 50 & 10 & 7 (1) & 6 & 0 & 0 \\
\hline & & 75 & 10 & $5(0)$ & 5 & 0 & 0 \\
\hline & & 100 & 10 & $5(1)$ & 3 & $1(69,70,76)$ & 0 \\
\hline & & 150 & 10 & $4(2)$ & 1 & $1(74,75,76)$ & 0 \\
\hline
\end{tabular}

* Parenthesis indicates No. of explants with no growth.

concentration. On the rooting medium, neither root nor shoot formation was observed in these explants by eight months of culture. In 'Kyoho' and KRi4x2181, the rate of survived explants treated for 30 days was slightly higher than those treated for 60 days.

\section{Variation of chromosome number}

Only tetraploid cells with 76 chromosomes were detected in root tips of 208 explants that showed normal growth (Fig. 2). Cells with $69(4 \mathrm{x}-7)$ chromosomes were exclusively found in root tips of a KRi4x2181 explant treated with $100 \mathrm{mg} / \mathrm{l} \mathrm{PFP}$ for 30 days, while those with only $72(4 \mathrm{x}-4)$ chromosomes were detected in a KRi4x2014 explant treated with $150 \mathrm{mg} / \mathrm{l} \mathrm{PFP} \mathrm{for} 30$ days. In vitro growth and morphology of these explants that reduced their several chromosomes appeared to be almost normal, although in vivo behaviour of these explants has not been examined yet. Cells with different number of chromosomes coexisted in root tips of three explants treated with 75 and $100 \mathrm{mg} / \mathrm{l} \mathrm{PFP}$ for 30 days and those of three explants treated with 100 and $150 \mathrm{mg} / \mathrm{l} \mathrm{PFP}$ for 60 days. The root tips of KRi4x 2181 explants consisted of three cells with different number of chromosomes, i.e., the cells with 76 chromosomes and a few cells with 69, 70, 74 or 75 chromosomes, while those of the others consisted of two cells with different number of chromosomes, i.e., the cells with $63,65,68$, $71,72,73,75$ or 76 chromosomes. These explants were considered to be mixoploid plants consisting of aneuploid cells with a maximum reduction of 13 chromosomes. In vitro growth of these mixoploid explants was appeared to be almost normal.

Chromosomal variations in seventeen explants showing very slow growth or no growth were not identified because no adventitious roots initiated in them in vitro.

\section{DISCUSSION}

The result of this study suggests that in vitro treatment of PFP to developing shoots of tetraploid grapes is effective for the elimination of a few chromosomes to induce aneuploid forms of them. However, Omura et al. (1987) reported that in vitro variants induced from PFP-treated 'Kyoho' shoots consisted of normal tetraploid cells together with a few 
cells with reduced chromosome number but almost all of the cells were euploid ( $2 x$ and $3 x$ ). The great difference between their and our results may be due to not only small difference in procedure of in vitro culture of shoots and PFP treatment but also difference in method of chromosome observation. Since Vitis has many and very small chromosomes of $n=1 \mathrm{x}=19$, exact count of chromosomes in root tip cells that were fixed by modified Carnoy's fluid and stained by aceto-orcein method (Omura et al., 1987) is very difficult, as their number increased more than diploid level. The enzyme maceration method that we used in combination with pretreatment of cells with 8-hydroxyquinoline and staining with Giemsa gave us beautiful mitotic figures from which chromosome counting was easily and exactly carried out. On the other hand, we did not find the variants with a few diploid and triploid cells reported by Omura et al. (1987). Although the reason of this is not obvious, it seems that these cells were eliminated during shoot development after PFP treatment and in subsequent subculture process, as aneuploid cells with chromosome number distant from tetraploid with 76 chromosomes were eliminated during the process.

In autotetraploid plants such as Vitis, hyper- and hypo-tetraploids show vigorous growth (Sybennga, 1992). Park et al. (2002) reported the occurrence of aneuploid seedlings from interploid crosses between triploids and tetraploids, and suggested that Vitis is a plant moderately patient to aneuploidy. Thus, cells with $75,74,73,72$ and 71 chromosomes were frequently survived in the PFP-treated explants. The appearance of cells with $75\left(4 x^{-1}\right), 74\left(4 x^{-2}\right)$ and $73\left(4 x^{-}-3\right)$ chromosomes and appearance of two aneuploid explants with $72(4 \mathrm{x}-4)$ and $69(4 \mathrm{x}-7)$ chromosomes suggest the possibility that in vitro treatment of PFP to tetraploid shoots induces hypotetraploid mutants.

If once the hyper- and hypo-tetraploid grapes were established from tetraploid cultivars or hybrids through elimination of one or two chromosomes, they could be easily propagated though grafting, even if the rates of induction of hyper- and hypo-tetraploid forms from the tetraploid grapes were very low.

\section{REFERENCES}

Ashikawa, K. 1972 On the new grape cultivar 'Takao'. Japan. J. Breed., 22: 46-51

Knight, R. L., A. P. Hamilton and E. Keep 1963 Somatic reduc- tion of chromosome number in a Riebes hybrid following treatment with para-fluorophenylalanine. Nature, 200: $1341-1342$

Lhoas, P. 1961 Mitotic haploidization by treatment of Aspergillus niger diploids with para-fluorophenylalanine. Nature, 190: 744

Murashige, T. and F. Skoog 1962 A revised medium for rapid growth and bioassays with tobacco tissue cultures. Physiol. Plant., 15: 473-497

Niizeki, H. and K. Fukui 1983 Elimination of somatic chromosome in strawberry plants by treatment with para-fluorophenylalanine. Japan. J. Breed., 33: 55-61

Notsuka, K., T. Tsuru and M. Shiraishi 2000 Induced polyploidy grapes via in vitro chromosome doubling. J. Japan. Soc. Hort. Sci., 69: 543-551

Omura, M. and T. Akihama 1980 Cellular variation in chromosome number induced by $p$-fluorophenylalanine in grape seedlings. HortScience, 15: 751-752

Omura, M. and T. Akihama 1981 Induced somatic reduction of chromosome number in a tetraploid grape shoot after $p$-fluorophenylalanine treatment. HortScience, 16: 653-654

Omura, M., K. Notsuka and T. Akihama 1985 Effect of $p$-fluorophenylalanine and amino acid derivatives on variation of somatic chromosome number in grape root tip cells. Japan. J. Breed., 35: 118-126

Omura, M., K. Notsuka, T. Hirabayashi and T. Akihama 1987 Variation in the chromosome number of cultured shoot tip of Vitis spp. by $p$-fluorophenylalanine treatment. Japan. J. Breed., 37: 125-132

Park, S. M., A. Wakana and M. Hiramatsu 1999a Most hypotetraploid seedlings from self-pollinated tetraploid grapes (Vitis complexes) have abnormal cotyledons. J. Fac. Agr. Kyushu Univ., 44: 81-89

Park, S. M., M. Hiramatsu and A. Wakana 1999b Aneuploid plants derived from crosses with triploid grapes through immature seed culture and subsequent embryo culture. Plant Cell, Tissue and Organ Culture, 59: 125-133

Park, S. M., A. Wakana, J. A. Kim, C. S. Jeong 2002 Male and female fertility in triploid grapes (Vitis complex) with special reference to the production of aneuploid plants. Vitis, $\mathbf{4 1}$ : $11-19$

Reisch, B. I. and C. Pratt 1996 Grapes. In "Fruit Breeding", Vol. 2, ed. by J. Janick and J. N. Moore, John Willey \& Sons, New York, pp. 297-369

Sinha, U. and S. S. Bhojwani 1976 Cytomorphological effect of $p$-fluorophenylalanine on Allium cepa. Acta Bota. Indica, $\mathbf{4}$ : $26-29$

Sybenga, J. 1992 Cytogenetics in Plant Breeding. Springer-Verlag, Berlin. pp. 469

Thao, N. T. P., Y. Miyajima, K. Ureshino, Y. Ozaki and H. Okubo $2003 p$-fluorophenylalanine-induced aneuploidy in Alocasia. J. Japan. Soc. Hort. Sci., 72: 299-305

Widholm, J. 1977 Selection and characterization of amino acid analog resistant plant cell culture. Crop Sci., 17: 597-600

Yamane, H., A. Kurihara and R. Tanaka 1978 Studies on polyploidy breeding in grapes. I. Chromosome numbers of large-sized grape varieties grown in Japan. Bull. Fruit Tree Res. Stn. E, 2: 1-8 (in Japanese with English summary) 